ISSN 0103-5665 • 117

\title{
COMPUlsão E DOMÍNIO NA NEUROSE OBSESSIVA: A MARCA DO PULSIONAL
}

\author{
Camila Peixoto Farias* \\ Marta Rezende Cardoso**
}

\section{Resumo}

Este artigo visa investigar os elementos presentes na base do desejo de domínio, próprio à neurose obsessiva. Trata-se de quadro clínico caracterizado pela busca compulsiva de domínio sobre si mesmo e sobre o outro. O ódio e a agressividade são centrais nessa patologia, engendrando uma dinâmica psíquica destrutiva, violenta. Esses aspectos despertaram a atenção de Freud, já o levando a investigar um aspecto até então obscuro em sua obra: a dimensão destrutiva da pulsão. A primeira confrontação da psicanálise com a problemática da compulsão se deu justamente a partir da análise dos sintomas obsessivos. Na neurose obsessiva, trava-se no sujeito uma árdua batalha intrapsíquica cuja marca é a condenação, o exercício de poder e a subjugação. Os neuróticos obsessivos permanecem cristalizados em torno de uma dinâmica mortífera, que se expressa de forma emblemática nas respostas que dão a ela, respostas que trazem também a marca de uma dominação.

Palavras-chave: neurose obsessiva; compulsão; domínio; onipotência.

\begin{abstract}
COMPULSION AND MASTERING IN OBSESSIONAL NEUROSIS: THE INSTINCTUAL TRACE This paper aims at studying the elements that form the basis of the desire to master, typical of obsessional neurosis. That is the clinical picture characterized by the compulsive pursuit of control on oneself and on the other. Hatred and aggression

* Programa de Pós-Graduação em Teoria Psicanalítica no Instituto de Psicologia da UFRJ. Rio de Janeiro, Rio de Janeiro, Brasil. E-mail: pfcamila@hotmail.com.

** Programa de Pós-Graduaçáo em Teoria Psicanalítica no Instituto de Psicologia da UFRJ. Rio de Janeiro, Rio de Janeiro, Brasil. E-mail: rezendecardoso@gmail.com.
\end{abstract}


are central in this pathology, engendering a violent and destructive psychic dynamics. These features stirred up Freud's attention, leading him to a hitherto obscure aspect in his work: the destructive dimension of the drive. The first confrontation of psychoanalysis to the problem of compulsion came exactly from the analysis of obsessional symptoms. In obsessional neurosis, the subject engages in a hard intrapsychic strife whose characteristic is condemnation, mastering and subjugation. The obsessional neurotics remain crystallized around a deadly dynamics emblematically expressed in responses that equally bear the mark of domination.

Keywords: obsessional neurosis; compulsion; mastering; omnipotence.

\section{Resumen}

COMPULSIÓN Y DOMINIO EN LA NEUROSIS OBSESIVA: LA MARCA DEL PULSIONAL

Este trabajo tiene como objetivo investigar los elementos que formarian la base del deseo de dominar, típico de la neurosis obsesiva. Es un cuadro clinico caracterizado por la búsqueda compulsiva de dominio sobre sí mismo y sobre el otro. El odio y la agresividad son centrales en esta patología, engendrando una dinámica psíquica violenta y destructiva. Estos aspectos despertaron la atención de Freud, y lo condujeron a investigar un aspecto hasta entonces oscuro en su obra: la dimensión destructiva de la pulsión. La primera confrontación del psicoanálisis con la problemática de la compulsión se produjo precisamente a partir del análisis de los sintomas obsesivos. En la neurosis obsesiva, el sujeto se empeña en una difícil batalla intrapsiquica cuya marca es condenación, ejercicio del poder y subyugación. Los neuróticos obsesivos permanecen cristalizados en torno a una dinámica mortífera que se expresa emblemáticamente en respuestas que traen también la marca de la dominación.

Palabras clave: neurosis obsesiva; compulsión; dominio; omnipotencia.

\section{Introdução}

Nos casos graves de neurose obsessiva o sujeito tem necessidade de se opor, argumentar infinitamente, frear toda iniciativa que não seja a sua. Seu objetivo é imobilizar o curso dos acontecimentos, fixar, petrificar o vivo, favorecer a inércia; ele exige o cumprimento rigoroso de suas condiçôes absolutas, visando criar um mundo sem falhas - que se parece com a morte. É nesse universo ordenado que o neurótico obsessivo faz sua morada, ocupando-se constantemente de sua manutenção. Estamos, portanto, diante de um eu blindado, entrincheirado, em 
alerta constante, e dos avatares de sua agressividade que é dirigida tanto contra si mesmo quanto contra o outro.

O sujeito torna-se, assim, um "tirano", exercendo seu domínio por meio de intrusões repetidas que violam a intimidade do outro. Ele exerce esse domínio no registro do poder e na ordem do dever, tanto de maneira ativa quanto sob a forma de resistência passiva, tendo como recurso frequente a força, a violência. Dessa forma, o ódio e a agressividade ganham destaque na dinâmica obsessiva como formas de domínio sobre o outro.

Nesse árido contexto, chama nossa atenção a busca desesperada e compulsiva pelo controle, pelo domínio sobre si mesmo e sobre o outro; enfim, sobre a vida como um todo. Mas o que estaria na base do desejo de domínio que encontramos nesse quadro clínico?

\section{O impacto da neurose obsessiva em Freud}

Zwangsneurose é o termo usado por Freud para designar a neurose obsessiva. Zwang designa um constrangimento interno, uma força interna imperativa, a compulsão. Não foi sem razão que Freud usou essa designação para essa modalidade de neurose, pois ela aponta para uma de suas principais características: o constrangimento interno, seja constrangimento a pensar (as obsessóes), seja constrangimento a agir.

De origem inconsciente e difícil de controlar, esse constrangimento interno leva o ego a se colocar repetitivamente em situaçóes que não fazem sentido para ele, pois a não realização dessas imposiçóes compulsivas é fonte de intensa e crescente angústia. Portanto, encontramos o mundo interno do neurótico obsessivo às voltas com a irrupção de uma força pulsional excessiva, o sujeito procurando fazer frente a ela por meio da construção de um compulsivo aparato defensivo.

A primeira confrontação de Freud à problemática da compulsão se deu justamente a partir da análise dos sintomas obsessivos. Foram eles que lançaram o primeiro raio de luz para a compreensão dessa exigência severa a que o ego náo pode se furtar. Segundo Assoun (1994), a neurose obsessiva é o solo sobre o qual a problemática da compulsão emerge na teoria freudiana.

O Z wang que a neurose obsessiva póe em relevo passa a interrogar a teoria freudiana, uma vez que desvela uma dimensão do funcionamento psíquico até então ignorada, e a compulsão surge, entâo, na teoria diretamente ligada à problemática do retorno do recalcado e à do sentimento de culpa, ou seja, referida ao ponto de vista da defesa egoica como motor do conflito psíquico. Dessa

Psic. Clin., Rio de Janeiro, vol. 25, N.I, P. I I7 - I 28, 2013 
forma, pode-se considerar que, sempre que uma compulsão neurótica tem lugar no funcionamento psíquico, é do recalcamento que ela provém. Neste momento da produçáo freudiana, a análise de um comportamento compulsivo remete necessariamente a uma dinâmica subjacente ligada à esfera da sexualidade (Assoun, 1994).

Como é sabido, no período inicial do estudo da neurose obsessiva a compreensão de Freud da dinâmica sexual estava calcada na teoria da sedução, que atribuía à lembrança de cenas reais de sedução papel determinante na etiologia das neuroses.

Porém a compreensão da dinâmica sexual subjacente à compulsão vem a sofrer profundas modificaçóes, sendo, assim, enriquecida. Freud renuncia à teoria da seduçâo a partir de 1897, abrindo espaço para a teoria da fantasia. A primeira teoria do trauma é modificada quando Freud concede estatuto de verdade à fantasia, à "realidade psíquica". A partir de então, a gênese da neurose é repensada e passa a ser situada na realidade dos desejos e das fantasias inconscientes: o recalcado diz respeito aos desejos sexuais infantis. $\mathrm{Na}$ neurose obsessiva, o recalcamento desses desejos revela-se frágil, aspecto que possui íntima relação com a dimensão compulsiva própria a esta patologia, especialmente no que concerne aos cerimoniais obsessivos, como mostraremos a seguir.

Em 1907, Freud publica "Atos obsessivos e práticas religiosas", no qual destaca a proximidade entre os atos obsessivos e as práticas através das quais os crentes expressam sua devoção. Nesse artigo, encontramos o detalhamento de um dos polos sintomáticos da neurose obsessiva: os rituais obsessivos ou atos compulsivos, caracterizados por obediência a leis desconhecidas, reguladoras do que seria permitido e do que estaria proibido. Segundo Freud, "[...] uma das condições da doença é o fato de que a pessoa que obedece a uma compulsão o faz sem compreender-lhe o sentido - ou, pelo menos, o sentido principal" (Freud, 1907/2006a, p. 113). A força da pulsão recalcada é vivida como tentação perigosa contra a qual o ego deve defender-se, cercando-se de medidas de proteção tais como os cerimoniais neuróticos.

Neste caso, o ego vê-se constantemente sob a ameaça do fracasso do recalque, o que dele exige esforço intenso e, ao mesmo tempo, constante para impedir tal emergência, processo que implica significativo dispêndio de energia. As medidas de proteçâo tendem a tornarem-se insuficientes contra a tentação, resultando, então, nas proibiçôes que visam manter à distância as situaçôes que podem dar origem a tentaçôes.

À primeira vista, os cerimoniais neuróticos consistem em meras formalidades destituídas de sentido. Porém são sempre executados como se o

Psic. Clin., Rio de Janeiro, vol. 25, N.I, P. I I 7 - I28, 2013 
sujeito tivesse de obedecer a leis secretas que náo podem ser desrespeitadas, o que gera intensa angústia em função da expectativa permanente de punição que assola o sujeito e advém do sentimento inconsciente de culpa.

Em seu mais famoso estudo de caso acerca da neurose obsessiva - "O Homem dos ratos" (1909) -, Freud indica que o ponto nodal desse tipo de conflito é um desejo agressivo, desejo de morte dirigido a um objeto amoroso (Laplanche, 1980). Este desejo está ligado à regressão à organização sádico-anal, que provoca a transformação das pulsôes sexuais, dirigidas ao objeto, em agressividade, em ódio. É por meio da noção de regressão que Freud (1909/2006b) apreende a importância das fantasias sádicas próprias à organização sádico-anal na neurose obsessiva. A libido, confrontada ao conflito edipiano, regride à organização sádico-anal, porém as satisfaçóes libidinais ligadas a esta se tornam inaceitáveis para o ego, que as recalca. A luta estabelece-se, portanto, entre o ego e as manifestações sexuais ligadas à organização sádico-anal.

A autopuniçáo obsessiva, expressa especialmente nas autorrecriminaçôes, indica a satisfação das tendências do sadismo e do ódio relacionadas ao objeto, que assim retornam para o próprio eu. Pelo caminho indireto da autopunição, o sujeito vinga-se do objeto original evitando a manifestação de sua hostilidade.

O sadismo recalcado, anteriormente dirigido ao objeto, segue sua açáo no inconsciente sob a forma de ódio, que retorna ao eu. Este permanece passivo diante das pulsóes sádicas e tenta escapar dessa posição passiva por meio de formaçóes reativas. Mas seu esforço muitas vezes não alcança êxito, o que resulta na intensificação das autopuniçóes. Estabelece-se, portanto, conflito intenso entre os sentimentos conscientes de afeição, os quais se exacerbam em função de se terem tornado reativos e, por outro lado, o sadismo ter persistido no inconsciente sob a forma de ódio. Estamos no cerne do intenso conflito de ambivalência que marca esta patologia: o ego passa a ser o campo de batalha onde esse combate se trava, comprometendo a capacidade de decisão, o que deixa o obsessivo abandonado ao império da dúvida, à paralisia do pensamento (Ménéchal, 2000).

Uma das formas adquiridas pela dúvida é a da indecisão que se apodera do sujeito a cada intençăo de agir; somente o agir compulsivo rompe esse domínio. Segundo Freud (1909/2006b), a compulsão seria a única forma de fazer frente ao império da dúvida. Porém o rompimento desse domínio possui caráter parcial, uma vez que na maioria das vezes os atos compulsivos ocorrem em dois tempos, sendo o primeiro anulado pelo segundo. A ação é ao mesmo tempo redobrada e anulada: repetir é ao mesmo tempo insistir e anular a primeira vez. Instaura-se uma lógica de anulação retroativa pela reiteração.

Psic. Clin., Rio de Janeiro, vol. 25, N.I, P. I I7 - I 28, 2013 
O ódio e a agressividade ganham a cena nesta patologia e engendram uma dinâmica destrutiva, violenta, conduzindo a atenção de Freud para um aspecto até então desconhecido: o aspecto destrutivo do pulsional. Sabemos que esse aspecto será efetivamente apreendido e teorizado por Freud a partir de 1920, com a postulaçẫo da segunda teoria das pulsóes (Freud, 1920/2006e). Vemos que a complexidade da neurose obsessiva começa a ser desvelada e, juntamente com ela, começa igualmente a se desvelar a complexidade do campo do pulsional, em particular a sua dimensão mortífera.

Segundo Assoun (1994), esses elementos caracterizam o contrato compulsivo desse tipo de neurose, marcado pelo imperativo do "dever fazer" cujo pano de fundo seria o de "não poder fazer". O cerne da compulsão comporta, portanto: defesa contra a tentação, perigo ligado a uma satisfação ilícita e medida de proteção contra o risco futuro de uma punição prevista ou de uma "desgraça" anunciada. De uma só vez, a compulsão constitui uma forma de não repetir o ato proibido e de, simultaneamente, praticá-lo. Por um lado, o ato compulsivo é uma homenagem à onipotência; por outro ele parece mascarar um vivido de impotência de caráter mais fundamental.

O sujeito acredita que seus pensamentos se tornarão, inevitavelmente, realidade. Essa onipotência nos fala da presença aqui de intelectualização e isolamento defensivos, além de um domínio de pulsóes parciais, como as de ver e de saber. Freud (1913/2006c) compara o neurótico obsessivo ao homem primitivo que recorre ao animismo e à magia para tentar explicar o mundo à sua volta. Não deixa, porém, de destacar que essa aproximação não cabe àquilo que se refere à problemática do ato, pois no homem primitivo o ato substitui a ideia, enquanto no obsessivo a ação encontra-se inibida e substituída pela ideia (Couvreur, 2003). Este aspecto é indicativo da regressão tópica do ato ao pensamento que aí tem lugar. A regressão do agir ao pensar apresenta-se, de fato, como um processo de base, como um dos elementos estruturais desta patologia.

O surgimento precoce e o recalque prematuro da pulsão de ver e de saber estáo intimamente relacionados a esse processo de regressão do ato ao pensamento. $\mathrm{O}$ ato é substituído, com a ajuda da pulsão de saber, por atos preparatórios do pensamento que, por sua vez, é sexualizado; “[...] a satisfação experimentada ao atingir um resultado cogitativo é percebida como uma satisfação sexual" (Freud, 1909/2006b, pp. 212-213). O pensamento é sustentado por uma energia normalmente reservada às ações. Portanto, na neurose obsessiva, os processos de pensamento sofrem uma espécie de desdobramento de energia, destinada originalmente ao agir, o que lhes confere justamente o seu caráter compulsivo.

Psic. Clin., Rio de Janeiro, vol. 25, N.I, P. I I7 - I28, 2013 
$\mathrm{Na}$ base da autopunição há a presença de um desejo agressivo recalcado o qual, como vimos anteriormente, é percebido como um ato efetivamente realizado, como crime cometido. Há, assim, um desdobramento importante do pensamento do crime (desejo proibido) ao crime de pensamento (desejo percebido como ato realizado). Vemo-nos, assim, diante de um crime de pensamento, âmago da problemática moral que caracteriza esta patologia (Laplanche, 1980).

O sentimento de culpa parece originar-se justamente do desejo recalcado, percebido como crime cometido. Como mostra Freud (1915/2006d), é próprio dos processos inconscientes que o desejo seja tratado como realidade - e, cabe complementar, na neurose obsessiva o pensamento parece manter sua característica infantil de onipotência pelo fato de ter havido regressão do ato ao pensamento.

O superego julga e condena o ego de forma implacável; sua ferocidade deve-se ao crime de pensamento do qual o ego não pode ser inocentado (Freud, 1915/2006d). A distinção entre fazer algo mau e desejar fazê-lo não se estabelece, pois o superego, por sua dimensão inconsciente, percebe os desejos como atos. Neste contexto, a problemática das raízes do sentimento inconsciente de culpa é retomada a partir de dois vértices: a impossibilidade de esconder do superego os desejos recalcados e a impossibilidade de o superego distinguir desejo e ato.

Portanto, o sentimento de culpa tem suas raízes no conflito entre o ego e o superego. Estabelece-se árdua batalha intrapsíquica, violenta dinâmica psíquica marcada pelo julgamento e pela condenação, pelo exercício de poder e pela subjugação. O neurótico obsessivo permanece siderado em torno dessa dinâmica mortífera - de dominaçáo interna - atualizada de forma emblemática pelas respostas que ele tenderá a dar a essa dinâmica, respostas, como veremos a seguir, também marcadas pela dominação.

\section{A relação de domínio na neurose obsessiva}

Dorey (2003) acredita que a sedução originária seria o protótipo de toda relação de domínio. $\mathrm{O}$ autor sublinha que, por meio dessa vinculação entre domínio e sedução, a dimensão de domínio estaria sempre presente na vida amorosa do homem, mas em graus muito variados. Acreditamos que a investigação desse entrelaçamento poderá iluminar aspectos importantes acerca da instauração da relaçáo de domínio no quadro da neurose obsessiva. Seguindo tais indicaçóes, centralizaremos nossa investigação em torno da relação inicial da criança com a figura materna.

Psic. Clin., Rio de Janeiro, vol. 25, N.I, P. I I7 - I28, 2013 
Como indicam Dorey (1981) e Kristeva (1988) a partir de suas observaçôes clínicas, na neurose obsessiva a relação inicial do bebê com a figura materna parece comportar características peculiares, expressas pelo pudor, pelo rigor, pela distância afetiva, pela escassez de contato físico e pela presença de exigência severa no plano moral. A mãe tende a exercer controle onipotente sobre o filho, dele exigindo total submissão, especialmente pelo controle severo de suas necessidades e cuidados na esfera do corpo.

Trata-se, no caso, de uma mãe extremamente dedicada, mas que apresenta dificuldade no reconhecimento das especificidades de seu bebê e de nele investir de forma mais efetiva, tendendo a se centrar no plano de suas necessidades. As demandas tendem a ser satisfeitas de modo imediato, e a relação primária é caracterizada pela satisfação ininterrupta das demandas do bebê, pelos cuidados excessivos, mas precários e tortuosos (por seu caráter reativo) no que concerne ao plano do investimento erótico. Para Dorey (1981), esses aspectos constituem a base de uma relação primária de caráter traumático. O autor nos alerta, porém, que, embora pareça estar ausente na história infantil dos neuróticos obsessivos, a seduçáo erótica efetiva age de forma indireta, por meio de formaçóes reativas.

Esse modo de relação da mãe com o bebê expressa, do ponto de vista da figura materna, também o caráter de uma reação, de uma defesa ao desejo "excessivo" que teria sido dirigido a ele, mas que veio a ser recalcado. Esse constante cuidado com a satisfação de necessidades é indicativo da posição em que o bebê fica situado: a de objeto do desejo da máe. Assim, estamos diante de uma situação de sedução destituída de sua dimensão mais diretamente erótica, "disfarçada" atrás dos severos e excessivos cuidados que invadem, via corpo, o espaço psíquico do sujeito.

De acordo com Kristeva (1988), a mãe do sujeito obsessivo pode ser caracterizada, em grande parte dos casos, como uma mãe deprimida, mas com a singularidade de procurar encobrir a doença mediante atividade exacerbada que, do ponto de vista do psiquismo do filho, tende a ser recebida como a marca de uma mãe severa. Essa atividade exacerbada da máe configura-se, no entanto, sob a forma de cuidados, de certa forma anônimos, que muitas vezes não se orientam especificamente ao filho, mas que se fazem presentes de modo inelutável. Os cuidados dirigidos ao filho visam fazer frente à depressão materna e o filho pode se tornar uma prótese fálica para a mãe deprimida.

Acrescenta Kristeva (1988) que a marca fundamental da depressão materna se revela no funcionamento psíquico do próprio sujeito obsessivo: a dissociação entre os afetos e a representação verbal. Aqui, porém, os afetos não são neutralizados, como ocorre no caso da depressáo materna: eles são atuados. $\mathrm{O}$ sujeito passa

Psic. Clin., Rio De JANEIRO, vol. 25, N.I, P. I I 7 - I 28, 2013 
a atuar a linguagem da seduçáo precoce, transformando-a em ato por meio da busca de realização imediata, mágica e compulsiva. Trata-se de linguagem desinvestida, acompanhada de um agir compulsivo fortemente investido. O neurótico obsessivo falaria duas línguas: uma secreta e não verbal - ligada à satisfação de sua demanda precoce endereçada a uma máe que responde complacentemente - e, por outro lado, uma linguagem e um pensamento neutralizados, mas que, paradoxalmente, comportam uma dimensão compulsiva, pulsional.

A hipótese da referida autora é que o obsessivo mantém a "mãe enterrada" em seu psiquismo, no sentido de uma mãe inelutavelmente "viva", demasiadamente presente, que exerce seu domínio ininterruptamente. A figura da "mãe enterrada" está referida a um estado de aprisionamento a um modo singular de relação com o objeto materno, indicativo da presença de uma identificação do sujeito com tal modo de relação.

Kristeva (1988) pontua a diferença importante entre a situação de crianças que, no início da vida, recebem entusiasmo e carinho e, em seguida, são postas de lado (em funçáo de repentino desinvestimento) e a de outras que, desde o início, são friamente acolhidas, sem investimento erótico, mas cujas necessidades são prontamente atendidas, até mesmo antecipadas. À primeira vista, poderíamos pensar que ambas estariam expostas ao mesmo fenômeno: o desinvestimento materno. Porém o caráter abrupto da exposição da criança, no primeiro caso, e a preocupação com a pronta satisfação de suas necessidades, no segundo, estabelecem matizes determinantes.

De acordo com Dorey (2003), essa relação primária traumática que encontramos na neurose obsessiva comporta uma dimensão identificatória que resulta de um duplo processo: por um lado, a mãe trata seu filho como objeto sexual diferenciado, como objeto de seu desejo; por outro lado, a criança adota essa posição, identificando-se com o objeto de desejo materno. A mãe, que deveria recusar essa posição adotada pelo filho, a reforça, colocando-o nesse lugar. $\mathrm{O}$ sujeito torna-se, entáo, prisioneiro dessa origem, desse tipo de relação que deixa uma marca - marca da figura daquele que exerce o domínio -, e vê-se, assim, condenado a repeti-la indefinidamente.

Essa modalidade de relação primária torna-se o protótipo da relação que o sujeito estabelecerá com o outro, protótipo de uma relação fundada sobre a anulação do desejo do outro. O sujeito tende, assim, a reproduzir - invertendo os lugares - esse modelo de relação infantil. Algo está interditado desde a origem para o sujeito, elemento denotativo de sua atividade sexual no futuro: a dimensão erótica da vida é barrada e a relação com o outro tende a se construir via ódio e agressividade. 
O sujeito permanece identificado com o lugar de objeto de desejo materno, aprisionado a essa modalidade de relaçáo, ponto de limite do trabalho de luto que teria que realizar ante sua perda, mantendo-a, nos termos de Kristeva (1988), "enterrada" em seu psiquismo pelo aprisionamento a esse modo de relação com o qual ele se identifica. Ele parece ter sido privado de suportes identificatórios que fornecessem as vias do prazer e limitassem a satisfação absoluta; permanece absorvido pela tarefa de manter tal sentimento de onipotência, identificado, como propóe Dorey (2003), com a relação onipotente que estabeleceu inicialmente com o objeto materno, e repetindo-a.

$\mathrm{Na}$ base da manutenção do sentimento de onipotência há uma relação com o objeto primário fortemente impregnada por uma sedução traumática, o que irá exigir do sujeito um amadurecimento defensivo precoce que trabalhará a serviço da manutenção de tal sentimento. Este parece se dar pela busca de domínio do mundo externo, especialmente pelo domínio de um outro sujeito.

\section{Busca de domínio na neurose obsessiva e na perversáo}

Roger Dorey (2003) traça interessante aproximação entre a problemática obsessiva e a perversa, indicando algumas semelhanças. Estas, porém, não dizem respeito à sintomatologia, mas ao modo de relaçáo com o objeto, considerando-se seu estatuto e sua função. Ao supor a existência de um tronco comum a essas duas patologias, o autor enfatiza que não se trata aqui apenas de duas problemáticas complementares, mas da intricação de dois processos mórbidos.

A hipótese é que tanto na neurose obsessiva, quanto na perversão, a meta final da dominação é o outro como "ser-de-desejo". Na perversão a relação de dominação se dá essencialmente no registro erótico, onde a arma é a sedução. A natureza da dominação do outro na perversão é especular, uma vez que este se torna vítima de captação pela imagem, já que lhe é proposto um desejo como reflexo do próprio desejo do sujeito. Já o obsessivo exerce a dominaçáo sobre o outro não no plano propriamente erótico, mas no "registro do poder e na ordem do dever" (Dorey, 2003, p. 118).

$\mathrm{O}$ autor propóe que tracemos a diferença e o parentesco entre as duas organizaçóes no plano da dinâmica pulsional. Na problemática perversa, a dominação sedutora é exercida por meio de uma posição de saber em relação ao outro: ele sabe o que vem a ser o desejo do outro. $\mathrm{O}$ jogo pulsional que se trava aí está no terreno de Eros, da ligação, as tendências libidinais prevalecendo sobre as destrutivas. Já o domínio exercido pelo obsessivo pode ser considerado como

Psic. Clin., Rio de Janeiro, vol. 25, N.I, P. I I 7 - I28, 2013 
de tipo totalitário: o outro deve agir da forma que ele considera adequada, deve pensar segundo as normas que ele impóe, desejar conforme o esquema traçado por ele e adotar sua concepção sobre a ordem das coisas. O neurótico obsessivo torna-se, assim, um tirano cujo exercício de domínio se dá por repetidas intrusões que violam a intimidade do outro.

Ele exerce esse domínio no registro do poder e na ordem do dever, tanto de maneira ativa quanto sob a forma de resistência passiva, frequentemente utilizando como recurso a força, a violência. Na problemática obsessiva, a dominação é feita, então, pela força - a posição é a de poder sobre o outro.

Ainda seguindo Dorey (2003), o objeto da ação destrutiva do obsessivo é o outro como ser desejante, o qual deve ser apagado, anulado. $\mathrm{O}$ obsessivo não pode suportar a singularidade do outro e, sobretudo, nenhuma manifestação de desejo erótico referido a si próprio. Tudo isso que deve ser evitado parece ser expressão de um desejo erótico diante do qual o sujeito vê-se incapaz de "responder", tornando-se, então, violento.

Nesse contexto, as variaçóes quanto à distância do objeto são insuportáveis, fazendo com que se tenha necessidade de dominar tudo que venha dele: movimentos, humores, opiniôes. Logo, encontramos um eu blindado, onipotente, mantido por constante estratégia de domínio, marcada, como pontuamos, pela agressividade. $\mathrm{O}$ obsessivo torna-se dependente do seu próprio sentimento de onipotência, que acaba por se manter pela submissáo do outro ao seu domínio. Para ele, essa submissão seria, em última instância, a prova do amor do outro, fundamental para o reconhecimento de si mesmo.

Há, no entanto, no exercício desse domínio um desejo de reconhecimento que pode ser expresso, segundo Dorey pela seguinte proposição: "Ama-me, mesmo sabendo que eu faço tudo para não ser amado e para destruir-te" (Dorey, 1981, p. 128; traduçáo nossa). Isto pode ser pensado como forma muito particular de mensagem endereçada ao outro, no sentido de uma convocaçáo, de uma expectativa de alguma resposta por parte deste.

A ação do neurótico obsessivo comporta duplo aspecto: além de visar o domínio sobre o outro - a negação de sua alteridade -, busca igualmente conseguir que o outro o reconheça, reconheça o seu desejo; isso restitui ao outro sua alteridade e, mais que isso, coloca-o em lugar privilegiado. O outro é destituído de sua alteridade mas, ao mesmo tempo, é investido como a alteridade da qual o obsessivo depende para o reconhecimento de si mesmo. Esta relação de domínio possui, portanto, caráter paradoxal: visa negar o outro como sujeito desejante e, ao mesmo tempo, visa o reconhecimento de si próprio.

Psic. Clin., Rio de Janeiro, vol. 25, N.I, P. I I7 - I 28, 2013 


\section{Referências}

Assoun, P.-L. (1994). La passion de répétition. Genèse et figures de la compulsion dans la métapsychologie freudienne. Revue Française de Psychanalyse, 2, 335-357.

Couvreur, C. (2003). Introdução aos escritos de Freud sobre a neurose obsessiva. In: Brusset, B. \& Couvreur, C. (orgs.). A neurose obsessiva (pp. 21-38). São Paulo: Editora Escuta.

Dorey, R. (1981). La relation d'emprise. Nouvelle Revue de Psychanalyse, 24, 117-140.

Dorey, R. (2003). Problemática obsessiva e problemática perversa. Parentesco e divergências. In: Brusset, B. \& Couvreur, C. (orgs.). A neurose obsessiva (pp. 115-139). São Paulo: Editora Escuta.

Freud, S. (2006a). Atos obsessivos e práticas religiosas. Obras completas, ESB, v. IX. Rio de Janeiro: Imago Editora. (Trabalho original publicado em 1907)

Freud, S. (2006b). Notas sobre um caso de neurose obsessiva. Obras completas, ESB, v. X. Rio de Janeiro: Imago Editora. (Trabalho original publicado em 1909).

Freud, S. (2006c). Totem e tabu. Obras completas, ESB, v. XIII. Rio de Janeiro: Imago Editora. (Trabalho original publicado em 1913)

Freud, S. (2006d). O inconsciente. Obras completas, ESB, v. XIV. Rio de Janeiro: Imago Editora. (Trabalho original publicado em 1915)

Freud, S. (2006e). Além do princípio do prazer. Obras completas, ESB, v. XVIII. Rio de Janeiro: Imago Editora. (Trabalho original publicado em 1920)

Kristeva, J. (1988). L’obsessionel et sa mère. Revue Française de Psychanalyse, 6, 1357-1371.

Laplanche, J. (1980). Problemáticas I - A angústia. São Paulo: Editora Martins Fontes.

Ménéchal, J. (2000). Résistance de la névrose obsessionnelle. In: Lara, M. \& Ménéchal, J. (orgs.). La névrose obsessionnelle - Contraintes et limites (pp. 61-128). Paris: Éditions Dunod.

Recebido em 8 de outubro de 2012 Aceito para publicação em 27 de março de 2013 